\title{
Electrochemical Characterization on Semiconductors p-Type CVD Diamond Electrodes
}

\author{
N. G. Ferreira ${ }^{1}$, L. L. G. Silva ${ }^{1,2}$, E. J. Corat ${ }^{1,3}$, \\ V. J. Trava-Airoldi ${ }^{1,3}$, K. Iha ${ }^{2}$ \\ 1: Instituto Nacional de Pesquisas Espaciais, \\ C.P. 515 - 12201-970 São José dos Campos, SP, Brazil \\ 2: Instituto Tecnológico de Aeronáutica, \\ 12228-900, São José dos Campos, SP, Brazil \\ 3: Universidade de São Francisco, \\ 13251-900, Itatiba, SP, Brazil
}

Received February 8, 1999

\begin{abstract}
Semiconductor boron-doped CVD diamond films were prepared on Si substrates by the hot filament technique. The surface morphology analysis by SEM presented continuous and well faceted films. The samples were grown with different boron concentrations by controlling the $B / C$ ratio in the feeding gas. Raman results showed a drastic change of diamond films for different doping levels. The characteristic line at $1332 \mathrm{~cm}^{-1}$ decreases and shifts to lower energy as a function of the film resistivity. It was also observed a broad peak around $1220 \mathrm{~cm}^{-1}$ caused by the incorporation of boron in the diamond lattice. Photocurrent-voltage behaviour of undoped and boron-doped diamond electrodes was investigated in dark and UV visible irradiation. The voltammograms showed that doped electrodes illuminated with a xenon lamp exhibited currents significatively higher because of the increased conductivity. For undoped electrodes it was observed a small photocurrent for anodic and cathodic polarization in the order of $\mu \mathrm{A}$ for the potential range of $+1.0 \mathrm{~V}$ and -1.0 $\mathrm{V}(\mathrm{Ag} / \mathrm{AgCl})$, for $1.0 \mathrm{M} \mathrm{KCl}$. Mott-Schottky plots studied the interfacial processes at diamondelectrolyte junction. The flatband potential $U_{f b}$ was found between 0.6 and $0.8 \mathrm{~V}(\mathrm{Ag} / \mathrm{AgCl})$ which varies with the presence of $\mathrm{sp}^{2}$-type carbon as an impurity. From the curve slope the acceptor concentrations were found in the range of $10^{18}$ and $10^{21} \mathrm{~cm}^{-3}$. These values agree with the estimated concentration obtained by Raman measurements.
\end{abstract}

\section{Introduction}

The evolution of research on semiconductor diamond has shown promising results with doping process during CVD growth. Due to its easy production and high stability, there is a great interest in studying the development of boron doped diamond leading to the application of these films as electrode for, photoelectrochemical (PEC) cells, sensors, etc [1-3].

The standard methods used for CVD boron-doped diamond were initially thermal diffusion $[4,5]$ and ion implantation $[6,7]$. These processes were made "ex situ", after the film growth. The main advantage is the no-contamination of the growth reactor. Martin et al. [4] have obtained highly doped films, using "in situ" process from a solid source of boron inside of the reactor. Better results that evidenced more homogeneous films were observed. CVD-grown polycrystalline diamond films, depending on growth conditions, can have a wide spectrum of electrophysical properties. Their properties depend on the concentrations of defects in diamond grains, on the volume fraction of the nondiamond intergrain boundary phase, and on its nature.

Okano et al [8] have proposed the boron doping during the CVD growth process using the hot filament reactor introducing $\mathrm{B}_{2} \mathrm{O}_{3}$ dissolved in methanol-acetona mixture, that works as a carbon source for diamond growth. Their results showed films with linear relation between the doping levels and boron concentration.

Pleskov et al. [9] have studied, for the first time, the electrochemical and PEC behaviour of diamond electrodes. Tenne and Swain $[10,11]$ have made cyclic voltammograms in the presence of redox couples. Sakharova et al. [12] have studied the mechanism of charge-transfer at the diamond/electrolyte interface. They have evaluated the flatband potential and the acceptor concentration. Patel et al. [13] have also studied the PEC behaviour of boron-doped diamond films. 
They concluded that their behaviour corresponds to a typical p-type semiconductor and these CVD diamond electrodes may be suitable for application as inert electrode.

The importance of PEC investigations for characterization of boron-doped diamond electrodes is the main purpose of this work. We have carried out PEC investigations from photoeffects measurements and MottSchottky plots. The morphology and film quality were analyzed by SEM and Raman spectroscopy. We have also evaluated the intrinsic stress from Raman spectra to show the effect of boron incorporation in the diamond lattice.

\section{Experimental}

The films were deposited on silicon substrate after seeding pre-treatment [14] in the usual hot filament-assisted CVD reactor. The films were grown at $800{ }^{\circ} \mathrm{C}$ during 6 hours. Boron source was obtained from a $\mathrm{H}_{2}$ line forced to pass through a bubbler containing $\mathrm{B}_{2} \mathrm{O}_{3}$ dissolved in methanol. This system permits the control of boron concentration using a flow controller for the gas inlet. The $\mathrm{CH}_{4}$ flow is kept at $0.5 \mathrm{sccm}$ for all experiments and the $\mathrm{H}_{2}$ and $\mathrm{B}_{2} \mathrm{O}_{3} / \mathrm{CH}_{3} \mathrm{OH} / \mathrm{H}_{2}$ flows are controlled in order to obtain the desired $B / C$ ratios. The dissolution of 5000, 10000, 15000 and $20000 \mathrm{ppm}$ of $\mathrm{B}_{2} \mathrm{O}_{3}$ in methanol was necessary to cover the whole range of $\mathrm{B} / \mathrm{C}$ ratios studied. Raman spectra were recorded using a Renishaw Microscope System 2000. PEC investigations were made using an electrochemical cell irradiated by a xenon lamp. The reference electrode and counter-electrode were $\mathrm{Ag} / \mathrm{AgCl}$ and platinum, respectively. The voltammograms were obtained in the potencial range of $+1.0 \mathrm{~V}$ and $-1.0 \mathrm{~V}$ using a solution of $1.0 \mathrm{M} \mathrm{KCl}$. The capacitance of the interface was measured using a potentiostat EGG/PAR 362 connected with a Lock-in EGG/PAR 124 and a $\mathrm{x}-\mathrm{y}$ recorder.

\section{Results and Discussion}

\section{a) SEM and Raman}

The surface analysis made by scanning electron micrograph for boron-doped diamond films showed a small variation on surface morphology by comparison with undoped diamond. The films are faceted with symmetrical and smooth faces with uniform texture that show a surface morphology with predominant (111) orientation. For all doping levels studied the films evidenced small grains of around $2-3 \mu \mathrm{m}$.
Raman spectroscopy is commonly used in characterizing the structure and quality of synthesized diamond films. A drastic change of Raman spectra of diamond films with different doping levels was observed. Fig. 1 shows the Raman spectra for samples obtained with $B / C$ ratios in the range 0 to $20000 \mathrm{ppm}$ in methanol. The characteristic diamond line at $1332 \mathrm{~cm}^{-1}$ decreases and downshifts to lower energy as the doping level of the film increases. For samples $D$ e $E(B / C=15000$ and $20000 \mathrm{ppm}$, respectively), this peak almost disappears and the broad peak at $1200 \mathrm{~cm}^{-1}$ becames more evident due to the incorporation of boron in the diamond lattice.

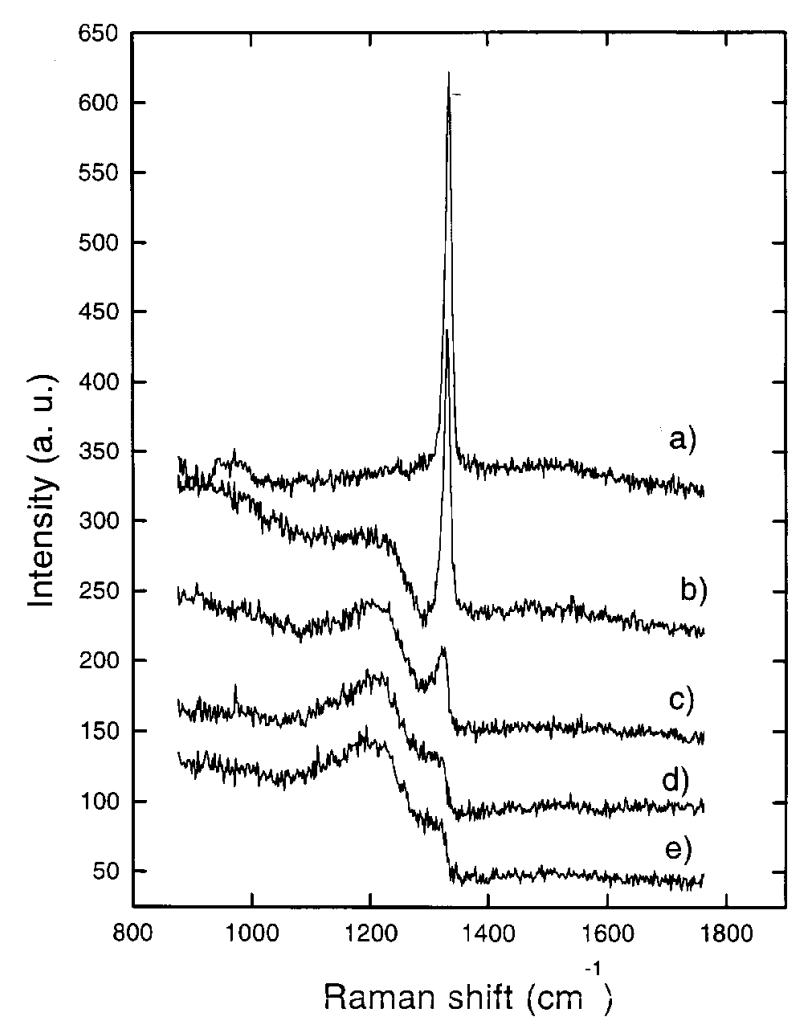

Figure 1. Raman spectra for undoped and boron-doped diamond films. a) $B / C=0 \mathrm{ppm}$, b) $B / C=5000 \mathrm{ppm}$, c) $B / C=10000 \mathrm{ppm}$, d) $B / C=15000 \mathrm{ppm}$, e) $B / C=20000$ pm.

\section{b) PEC investigations}

\section{Photocurrent-voltage behaviour}

Photoelectrochemical analysis are of fundamental importance in order to explore the attractive electronic properties of diamond electrode. PEC investigations on p-type diamond would enhance the understanding of photoeffects in the diamond-electrolyte system and diamond itself.

For a preliminary analysis of these processes, the current-voltage (I-V) behaviour of undoped and doped 
diamond electrodes was investigated in dark and under UV-visible irradiation. A typical voltammogram of a doped electrode $(B / C=20000 \mathrm{ppm}$ in methanol) is shown in Fig. 2. It was observed that the anodic current presents an increase of $100 \%$ under irradiation. The same measurements were made for undoped electrode. Small photocurrents under anodic as well as cathodic polarization were also observed. The results showed anodic current 20 times smaller than for highly doped film. The generation of photocurrent and its dependence on potential indicate the semiconducting nature of the electrode and the formation of a Schottkytype barrier.

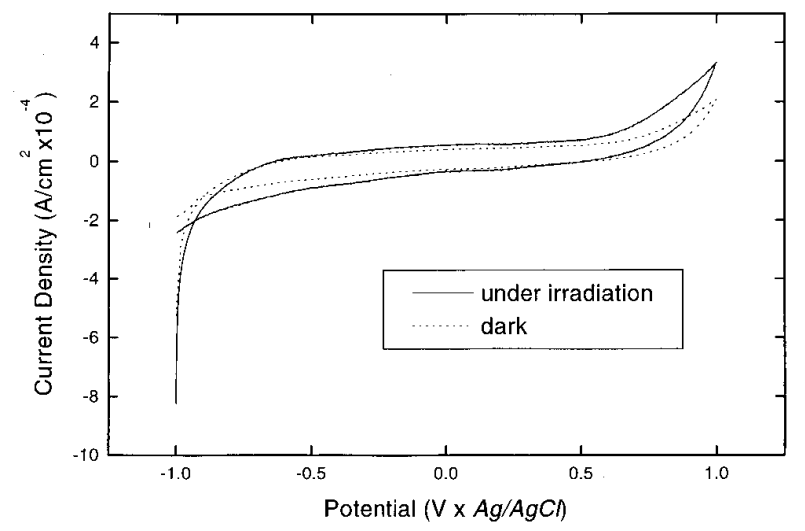

Figure 2. I-V curves at boron-doped diamond electrode in the dark (dot line) and under irradiation (straight line), electrolyte $1.0 \mathrm{M} \mathrm{KCl}$.

\section{Mott-Schottky plots}

The measurements of differential capacitance in the space charge region or depletion layer for semiconductor/electrolyte interface can extend the understanding of the interfacial process. This measurement permits to find the flatband potential and the energy bands of diamond with respect to the redox potential. Besides, the dependence of differential capacitance $C$ with potential $V$ of a depletion layer also allows the evaluation of the acceptor concentration, with the equation $[15,16]$ :

$$
N_{A}=\frac{2}{e \varepsilon_{0} \varepsilon}\left[d\left(C^{-2}\right) / d V\right]^{-1}
$$

Here $e$ is the electron charge; $\varepsilon_{0}$ and $\varepsilon$ are the permittivity of vacuum and semiconductor, respectively.

The differential capacitance study was also made for samples with different doping levels, in the range of $B / C=0$ and $20000 \mathrm{ppm}$ in methanol. According to such analysis, the Mott-Schottky plots were more linear in the anodic region of the potential $x \mathrm{Ag} / \mathrm{AgCl}$ and 1.0 $\mathrm{M} \mathrm{KCl}$ for all electrodes studied, in the frequency of 1 $\mathrm{kHz}$. The acceptor concentration $N_{A}$ and the flatband potential $U_{f b}$ were determined from the slope and the intercept of the linear region of the M-S plot. The flatband potential $U_{f b}$ were found between 0.6 and $0.8 \mathrm{~V}$ $x \mathrm{Ag} / \mathrm{AgCl}$, that agree with the values showed in other works $[9,17,18]$. The acceptor concentrations were also evaluated for all samples studied. For a doping level with $B / C$ ratio in the $5000-20000 \mathrm{ppm}$ range the acceptor densities were found in the range $1,9 \times 10^{19}$ $1,5 \times 10^{21} \mathrm{~cm}^{-3}$. These are highly doped films and the acceptor densities are in close agreement with the $B / C$ ratio and with the estimation from Raman spectra [19]. These measurements show that the Mott-Schottky plot method is valid for highly doped films. Fig. 3 shows the dependence of capacity on the electrode potential, for the boron-doped electrode for $B / C=20000 \mathrm{ppm}$, that correspond an acceptor concentration of $1.5 \times 10^{21}$ $\mathrm{cm}^{-3}$. The flatband potential determined from the intercept on $\mathrm{x}$-axis was $0.75 \mathrm{~V} x \mathrm{Ag} / \mathrm{AgCl}$.

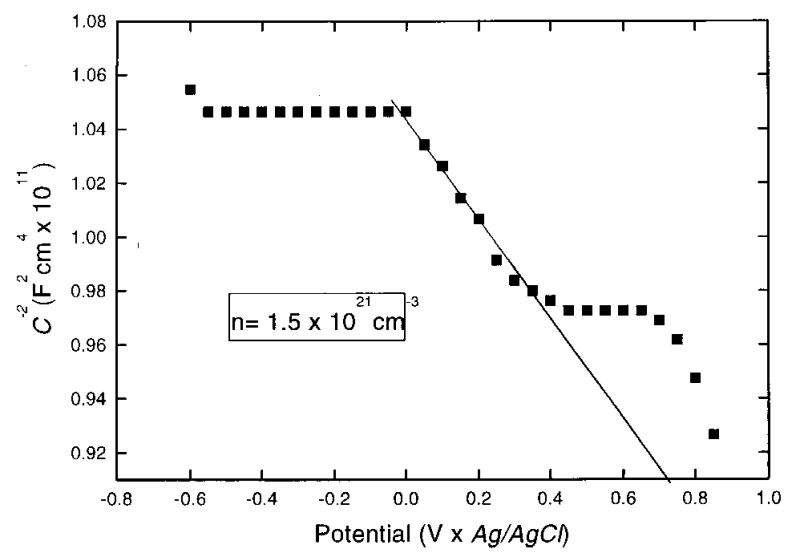

Figure 3. Mott-Schottky plots of boron-doped diamond electrode, where $C$ is the capacitance and $V$ is the electrode potential, at $1 \mathrm{kHz}$ and eletrolyte $1.0 \mathrm{M} \mathrm{KCl}$.

\section{Conclusion}

We have made a series of experiments using borondoped diamond films by controling different doping levels. SEM analyses have shown uniform and symmetrical films and smooth faces with predominant (111) orientation. Raman study evidenced high doped films showing a decrease of characteristic diamond line at $1332 \mathrm{~cm}^{-1}$ and a line shift to lower energy as a function of the doping level. For samples $D$ e $E(B / C=15000 \mathrm{ppm}$ and $20000 \mathrm{ppm}$, respectively), this peak almost disappears and the broad peak at $1200 \mathrm{~cm}^{-1}$ becomes more evident due to the boron incorporation in the diamond lattice.

PEC investigations have shown a typical photocurrent - voltage behaviour for p- type semiconductor. It 
was observed that the anodic current presents an increase of $100 \%$ under irradiation. The same measurements were made for the undoped electrode. Small photocurrents under anodic as well as cathodic polarization were also observed, but by comparison with the doped film, this electrode presented an anodic current 20 times smaller. The generation of photocurrent and its dependence on potential indicate the semiconducting nature of the electrode and the formation of a Schottky-type barrier. The differential capacitance study has permitted to evaluate the flatband potential and the acceptor concentrations. The values obtained for $U_{f b}$ were found between 0.6 and $0.8 \mathrm{~V} x \mathrm{Ag} / \mathrm{AgCl}$ and agree with the range showed in the literature. Acceptor densities were found in the range of $10^{19}$ to $10^{21} \mathrm{~cm}^{-3}$, that evidences high doped films and are in good agreement with Raman results.

\section{References}

[1] H. Spicka, M. Griesser, H. Hutter, M. Grasserbauer, S. Bohr, R. Haubner, B. Lux, Diam. Relat. Mat., 5, 383 (1996).

[2] G. Popovici, M.A. Prelas, Diam. Relat. Mat., 4, 1305 (1995).

[3] G.R. Brandes, C.P. Beetz, C. A. Feger, R.L. Wright, Diam. Relat. Mat., 4, 586 (1995).

[4] H.B. Martin, A. Argotia, U. Landau, A.B. Anderson, J.C. Angus, J. Electrochem. Soc., 143 (6), 133 (1996).

[5] R. DeClements, B. L. Hirsche, M. C. Granger, J. Xu, G.M. Swain, J. Electrochem. Soc., 143 (7), 150 (1996).

[6] F. Fontaine, A. Deneuville, E. Gheeraert, P. Gonon, L. Abello, G. Lucazeau, Diam. Relat. Mat., 3, 623 (1994).
[7] E. Gheeraert, F. Fontaine, A. Deneuville, Y.L. Khong, A.T. Collins, Diam. Relat. Mat., 3, 737 (1994).

[8] K. Okano, Y. Akiba, T. Kurosu, M. Lida, T. Nakamura, J. Crystal Growth, 99, 1192 (1990).

[9] Yu. V. Pleskov, A. Ya. Sakharova, M. D. Krotova, L.L. Bouilov, and B.V. Spitsyn, J. Electroanal. Chem., 228, 19 (1987).

[10] R. Tenne, K. Patel, K. Hashimoto, and A. Fujishima, J. electrochem. Soc., 347, 409 (1993).

[11] G.M. Swain and R. Ramesham, Anal. Chem., 65, 345 (1993).

[12] A. Ya. Sakharova, A. E. Sevastyanov, Yu. V. Pleskov, G.L. Teplitskaya, V.V. Surikov, and A.A. Voloshin, Elektrokhimiya, 27, 239 (1991).

[13] K. Patel, K. Hashimoto and A. Fujishima, J. Photochem. Photobiol. A, 65, 419 (1992).

[14] R. C. Mendes de Barros, E. J. Corat, N. G. Ferreira, T. M. Souza, V. J. Trava-Airoldi, N. F. Leite and K. Tha. Diamond and Related Materials, 5, 1323 (1996).

[15] A.J. Bard and L.R.Faulner, Electrochemical MethodsFundamentals and Applications, John Wiley \& Sons, p. 630,1980 .

[16] A.D. Modestov, Yu.V. Pleskov, V. P. Varnim, and I.G. Teremetskaya, Russian Journal of Electrochemistry, 33 (1), 55 (1997).

[17] A. Ya. Sakharova, Yu. V. Pleskov, F. Di quarto, S. Piazza, C. Sunseri, I. G. Teremetskaya, and V.P. Varnin, J. electrochem. Soc., 142, 2704 (1995).

[18] L. Boonma, T. Yano, D.A. Tryk, K. Hashimoto, and A. Fujishima, J. Electrochem. Soc., 144 (6) L142 (1997).

[19] R.J. Zhang, S.T. Lee, Y.W.Lam, Diam. Relat. Mat., 5, $1288(1996)$. 